\title{
Uma Nota Sobre Amortização de Dívidas: Juros Compostos e Anatocismo
}

\author{
Clovis de Faro*
}

\author{
Conteúdo: 1. Introdução; 2. 0 Caso de Um Esquema Geral de Financiamento; 3. Casos \\ Particulares; 4. 0 Caso de Prestações em Atraso; 5. Conclusão; A. Apêndice - 0 \\ Caso de Concessão de Carência. \\ Palavras-chave: Tabela Price; Juros Compostos; Anatocismo. \\ Códigos JEL: E4, E5.
}

Motivado pelo debate sobre se financiamentos segundo a Tabela Price é a juros compostos e se implica em anatocismo, esta nota, tomando como ponto de partida um caso mais geral, busca lançar luz sobre a discussão.

Motivated by the debate whether or not the amortization system of constant payments, which in Brazil is known as Tabela Price, conforms with the principle of compound interest and implies what the judiciary names as anatocism, that is incorporation of interest to the loan principal, this note, considering a more general system of loan repayment, aims to shed some light on the subject.

\section{INTRODUÇÃO}

Uma questão que tem provocado muita polêmica, principalmente em querelas judiciais que envolvem demandas no que concerne à adoção da popular Tabela Price em financiamentos (mormente os habitacionais), diz respeito ao fato de haver ou não a presença do que, no jargão jurídico, se denomina de anatocismo. Ou seja, como nos ensina mestre Aurélio Buarque de Holanda Ferreira (cf. de Holanda Ferreira, 1999, p. 133), se o emprego da Tabela Price acarreta "capitalização dos juros de uma importância emprestada"; o que se tem constituído em anátema em nossos tribunais.

Sendo que, obviamente, em havendo capitalização de juros, o que implica na ocorrência de anatocismo, necessariamente, ter-se-á juros devido a juros. O que significa dizer que anatocismo tem como consequência juros compostos.

Que o assunto continua sendo objeto de muita controvérsia, pode ser constatado em uma rápida visita à Internet. Com o auxílio da ferramenta de busca Google, teclando-se Tabela Price, iremos nos deparar com uma verdadeira pletora de artigos e comentários, muitos deles agressivos e ensejando acirrados embates, contestando a presença, ou não, tanto do regime de juros compostos como o do anatocismo.

0 presente artigo, que pode ser interpretado como em sequência, agora mais formal, ao publicado em de Faro (2009, pp. 120-129), que colimou mostrar a inaquadebilidade do regime de juros simples em financiamentos com mais de um pagamento, tem dois propósitos:

\footnotetext{
*Professor da Escola Brasileira de Economia e Finanças, Fundação Getulio Vargas - EPGE/FGV. E-mail: clovis . faro@f gv . br
} 
$1^{\circ}$ ) demonstrar que qualquer sistema de amortização de dívidas cujo valor financiado seja liquidado mediante o pagamento de (duas ou mais) prestações periódicas, o que significa dizer que há equivalência financeira entre o valor do empréstimo e a sequência de prestações, implica em que, conquanto implicitamente, esteja ocorrendo o emprego do regime de capitalização dito de juros compostos;

$2^{\circ}$ ) evidenciar que, se cada prestação periódica cobrir os juros devidos ao saldo devedor, e não existir prestações em atraso, não haverá a ocorrência, ao menos em uma interpretação estrita, de anatocismo.

Em outras palavras, o objetivo é o de, à luz dos princípios básicos da Matemática Financeira, que podem ser encontrados em, por exemplo, de Faro e Lachtermacher (2012, especialmente os capítulos 1 e 3), explicitar que qualquer esquema de amortização de dívidas que se conforme com a sistemática aqui enunciada, com a Tabela Price sendo um mero, embora importante, caso particular, tem como consequência a, o que a muitos poderia parecer paradoxal, simultânea ocorrência da presença do regime de juros compostos e da ausência de anatocismo.

Fundamentalmente, iremos evidenciar que, enquanto que, como mencionado, a ocorrência de anatocismo implica em juros compostos, podemos ter a aplicação do regime de juros compostos sem que se verifique a presença de anatocismo.

Subsidiariamente, considerando ainda dois outros casos particulares bastante populares, o Sistema Americano e o de Amortizações Constantes, são também cotejadas algumas de suas características.

\section{O CASO DE UM ESQUEMA GERAL DE FINANCIAMENTO}

Preliminarmente, lembremos que, o que admitiremos ser de conhecimento comum, o chamado regime de juros compostos se caracteriza pelo fato de ocorrer juros devido a juros. Isto é, em contraste com o regime dito de juros simples, onde não há a capitalização dos juros, no regime de juros compostos os juros formados a cada período, que não sejam pagos, ${ }^{1}$ rendem juros nos períodos seguintes.

Por outro lado, como o anatocismo é identificado pela cobrança de juros sobre juros, sua realização só pode ocorrer no regime de juros compostos. Entretanto, como veremos, mesmo estando subjacente o regime de juros compostos, a hipótese, nas condições que iremos explicitar, de pagamento periódico dos juros não acarreta ocorrência de anatocismo.

Isto posto, tomando como ponto de partida um caso bastante geral, do qual, como veremos, a Tabela Price, entre outros populares sistemas de amortização de dívidas, como o de Amortizações Constantes, é um caso particular, consideremos a situação onde um financiamento de valor $F$, deva ser resgatado por intermédio do pagamento de $n$, com $n>1$ (se $n=1$ teremos a situação, trivial, onde não há distinção entre os regimes de juros simples e o de juros compostos), prestações periódicas e postecipadas (isto é, pagas no fim de cada período). Com a primeira ocorrendo no fim do primeiro período. ${ }^{2}$

Denotando-se por $p_{k}$ o valor da $k$-ésima prestação e, neste caso mais geral, por $i_{k}$ a taxa periódica de juros, sob forma dita unitária, que houver sido pactuada para vigorar no $k$-ésimo período, para $k=1,2, \ldots, n$, admita-se que tenha sido estipulado que, a cada período, a correspondente prestação $p_{k}$ cubra sempre a remuneração, devida a juros, relativa ao saldo devedor (estado da dívida) no início do período considerado. ${ }^{3}$ Isto é, representando-se por $S_{k}$ o saldo devedor (principal remanescente) no início do $k$-ésimo período, logo após o pagamento da $k$-ésima prestação, é suposto que

\footnotetext{
${ }^{1}$ Efetivamente, temos aqui uma sutileza. Mesmo que os juros periódicos sejam pagos, como no caso do Sistema Americano, o regime que está implícito, como veremos, é o de juros compostos.

${ }^{2}$ Ou seja, estaremos admitindo que não haja carência. O caso com carência será tratado, através de um exemplo simplificado, no Apêndice.

${ }^{3}$ Estaremos admitindo que cada taxa de juros $i_{k}$ seja positiva. Ou seja, ao menos na forma dita aparente, e portanto antes de efeitos inflacionários, as taxas de juros, como é o caso normal, são supostas sempre positivas.
} 


$$
p_{k} \geq i_{k} S_{k-1}, \quad \text { para } \quad k=1,2, \cdots, n
$$

$\operatorname{com} S_{0} \equiv F$.

Ainda mais, estaremos supondo um esquema de amortização dito financeiramente consistente (no sentido de que o débito seja liquidado com o pagamento da última prestação).

Para nossos propósitos, denote-se por $a_{k}$ a parcela de amortização (ou de redução do estado da dívida) que é suposta estar embutida na $k$-ésima prestação. Contabilmente, tem-se que:

$$
a_{k}=p_{k}-i_{k} S_{k-1}, \quad \text { para } \quad k=1,2, \cdots, n
$$

Observe-se que, face à restrição expressa por (1), as parcelas de amortização, quando positivas, são todas de redução do principal financiado $F$.

Obviamente, para que a dívida seja liquidada quando do pagamento da última prestação, $p_{n}$, é necessário que se tenha

$$
\sum_{k=1}^{n} a_{k}=F
$$

Deve ser ressaltado que, mantidas as hipóteses já mencionadas, teremos $a_{k} \geq 0$, para $k=1,2, \ldots$, $n-1$, com ao menos $a_{n}>0$. Isto é, conquanto possam ocorrer amortizações nulas, no mínimo a última é estritamente positiva.

Face às definições, tem-se que:

$$
S_{k}=S_{k-1}-a_{k}, \quad k=1,2, \cdots, n, \quad \text { com } \quad S_{0} \equiv F
$$

do que decorre, recursivamente, que

$$
S_{k}=F-\sum_{\ell=1}^{k} a_{\ell}, \quad k=1,2, \cdots, n, \quad \text { com } \quad S_{n}=0
$$

Não havendo prestação em atraso, o que iremos inicialmente supor, pode-se afirmar que, em nenhuma eventualidade, há pagamento de juros sobre juros. Isto porque somente se paga juros sobre o saldo devedor remanescente; que é sempre não crescente. Ou seja, formalmente, não ocorre o chamado anatocismo.

Entretanto, como iremos mostrar, por haver a equivalência financeira entre a sucessão de prestações e o valor financiado $F$, o que implica na validade da relação

$$
\begin{aligned}
F \prod_{k=1}^{n}\left(1+i_{k}\right) & =p_{1} \prod_{k=2}^{n}\left(1+i_{k}\right)+p_{2} \prod_{k=3}^{n}\left(1+i_{k}\right)+\cdots+p_{n-1}\left(1+i_{n}\right)+p_{n} \\
F \prod_{k=1}^{n}\left(1+i_{k}\right) & =\sum_{k=1}^{n-1} p_{k} \prod_{\ell=k+1}^{n}\left(1+i_{\ell}\right)+p_{n}
\end{aligned}
$$

está implícito que o sistema genérico de amortização que está sendo considerado, conforma-se com o princípio do regime de juros compostos. Em outras palavras, e de uma maneira algo paradoxal, embora esteja sendo, conquanto implicitamente, considerado o regime de juros compostos, não há ocorrência de anatocismo.

Para mostrarmos a validade da relação (6), observe-se inicialmente que o saldo devedor na época $k, S_{k}$, pode ser entendido como resultante do acréscimo, devido a juros, à taxa $i_{k}$, do saldo devedor na época $k-1$, deduzido da prestação $p_{k}$ que se acaba de pagar. Isto é: ${ }^{4}$

\footnotetext{
${ }^{4}$ Note-se que, trivialmente, a relação (7) implica na relação (4), pois:
} 


$$
S_{k}=\left(1+i_{k}\right) S_{k-1}-p_{k}, \quad k=1,2, \cdots, n
$$

Portanto, recursivamente, tem-se que:

$$
\begin{aligned}
k & =1: S_{1}=\left(1+i_{1}\right) S_{0}-p_{1}=F\left(1+i_{1}\right)-p_{1} \\
k & =2: S_{2}=\left(1+i_{2}\right) S_{1}-p_{2}=F\left(1+i_{1}\right)\left(1+i_{2}\right)-p_{1}\left(1+i_{2}\right)-p_{2} \\
k & =3: S_{3}=\left(1+i_{3}\right) S_{2}-p_{3}=F\left(1+i_{1}\right)\left(1+i_{2}\right)\left(1+i_{3}\right)-p_{1}\left(1+i_{2}\right)\left(1+i_{3}\right)-p_{2}\left(1+i_{3}\right) \\
& -p_{3} \\
k & =4: S_{4}=\left(1+i_{4}\right) S_{3}-p_{4}=F\left(1+i_{1}\right)\left(1+i_{2}\right)\left(1+i_{3}\right)\left(1+i_{4}\right)-p_{1}\left(1+i_{2}\right)\left(1+i_{3}\right)\left(1+i_{4}\right) \\
& -p_{2}\left(1+i_{3}\right)\left(1+i_{4}\right)-p_{3}\left(1+i_{4}\right)-p_{4}
\end{aligned}
$$

Ou seja, por extensão, vemos que:

$$
S_{k}=F \prod_{\ell=1}^{k}\left(1+i_{\ell}\right)-\sum_{\ell=1}^{k-1} p_{\ell} \prod_{j=\ell+1}^{k}\left(1+i_{j}\right)-p_{k}, \quad k=1,2, \cdots, n
$$

Ora, como devemos ter $S_{n}=0$, segue-se que, para $k=n$

$$
S_{n}=0=F \prod_{k=1}^{n}\left(1+i_{k}\right)-\sum_{k=1}^{n-1} p_{k} \prod_{\ell=k+1}^{n}\left(1+i_{\ell}\right)-p_{n}
$$

o que demonstra a validade da equivalência, no regime de juros compostos, entre a sucessão de prestações e o valor financiado.

Deve ser observado que, conquanto a relação de equivalência financeira, expressa por (6), tome como data focal a época $n$, é imediato que, face a propriedade de cindibilidade do prazo, que é característica do regime de juros compostos, a equivalência financeira deve também estar presente quando se toma como data focal a época do empréstimo. Isto é, devemos ter:

$$
F=\sum_{k=1}^{n} p_{k} \prod_{\ell=1}^{k}\left(1+i_{\ell}\right)^{-1}
$$

Para mostrar que (8) implica (6), e vice-versa, multiplique-se ambos os membros de (8) por $\prod_{k=1}^{n}(1+$ $\left.i_{k}\right)$.

Tem-se:

$$
S_{k}=\left(1+i_{k}\right) S_{k-1}-p_{k}=S_{k-1}-\left(p_{k}-i_{k} S_{k-1}\right)=S_{k-1}-a_{k} .
$$




$$
\begin{aligned}
F \prod_{k=1}^{n}\left(1+i_{k}\right) & =\prod_{k=1}^{n}\left(1+i_{k}\right)\left\{p_{1} \prod_{\ell=1}^{1}\left(1+i_{\ell}\right)^{-1}+p_{2} \prod_{\ell=1}^{2}\left(1+i_{\ell}\right)^{-1}+p_{3} \prod_{\ell=4}^{3}\left(1+i_{\ell}\right)^{-1}\right. \\
& \left.+\cdots+p_{n-1} \prod_{\ell=1}^{n-1}\left(1+i_{\ell}\right)^{-1}+p_{n} \prod_{\ell=1}^{n}\left(1+i_{\ell}\right)^{-1}\right\} \\
& =p_{1} \prod_{k=2}^{n}\left(1+i_{k}\right)+p_{2} \prod_{k=3}^{n}\left(1+i_{k}\right)+p_{3} \prod_{k=4}^{n}\left(1+i_{k}\right)+\cdots \\
& +p_{n-1} \prod_{k=n}^{n}\left(1+i_{k}\right)+p_{n} \\
& \text { ou } \prod_{k=1}^{n}\left(1+i_{k}\right)=\sum_{k=1}^{n-1} p_{k} \prod_{\ell=k+1}^{n}\left(1+i_{\ell}\right)+p_{n}
\end{aligned}
$$

Por outro lado, reiteremos, como sempre, a cada período, há o integral pagamento dos juros devidos, não há a ocorrência de anatocismo.

\subsection{A Falácia de que Esteja Subjacente o Regime de Juros Simples}

Ora, poderão argumentar alguns céticos, se não há anatocismo o regime de capitalização subjacente é o de juros simples. Ou seja, visto que não esteja ocorrendo a capitalização de juros sobre a importância emprestada, há que esteja sendo (conquanto implicitamente) considerado o regime de juros simples.

Para evidenciar a falácia de tal entendimento, lançaremos mão de um extremamente simples exemplo numérico.

Seja o caso onde o empréstimo de $\mathrm{R} \$ 100.000,00$ deva ser resgatado mediante o pagamento de duas prestações anuais. Tendo sido estipulado que as taxas anuais de juros sejam $i_{1}=i_{2}=10 \%$, e se, arbitrariamente, houver sido acordado entre as partes interessadas que a primeira parcela de amortização seja $a_{1}=\mathrm{R} \$ 30.000,00$, segue-se das relações (2) e (4) que:

$$
p_{1}=30.000+0,1 \times 100.000=R \$ 40.000,00
$$

e

$$
S_{1}=100.000-30.000=R \$ 70.000,00
$$

Portanto, como, face a relação (3), $a_{2}=\mathrm{R} \$ 70.000,00$, tem-se:

$$
p_{2}=70.000+0,1 \times 70.000=R \$ 77.000,00
$$

do que decorre que a dívida seja efetivamente liquidada, pois que

$$
S_{2}=70.000(1+0,1)-77.000=0
$$

Muito embora, tal como aqui numericamente ilustrado, seja obedecida a relação de equivalência financeira relativa ao regime de juros compostos, expressa pela relação (6), uma vez que

$$
100.000(1+0,1)(1+0,1)=121.000=40.000(1+01)+77.000
$$

a correspondente relação de equivalência financeira, no regime de juros simples, não o é, pois que

$$
100.000(1+2 \times 0,1)=120.000 \neq 40.000(1+0,1)+77.000=121.000
$$


Relação de equivalência financeira esta que também não é satisfeita quando se toma como data focal a da concessão do financiamento; já que:

$$
100.000 \neq 40.000 /(1+0,1)+77.000 /(1+2 \times 0,1)=100.530,30
$$

A conclusão aqui, que, deve ser frisado, independe do particular exemplo considerado, é que o fato de que não ocorra anatocismo não implica em que o regime de juros subjacente seja o de juros simples.

\section{CASOS PARTICULARES}

Na prática corrente, aqui entre nós, ao menos na data de assinatura do contrato de financiamento, o usual é estabelecer-se que a taxa periódica de juros que será cobrada seja tomada como constante e igual a $i$. Isto é, a preços da data da assinatura do contrato, a relação básica de equivalência financeira entre o valor financiado $F$, e a sucessão de $n$ prestações periódicas, é tal que (tendo em vista a relação (6)):

$$
F(1+i)^{n}=\sum_{k=1}^{n-1} p_{k}(1+i)^{n-k}+p_{n}
$$

ou

$$
F(1+i)^{n}=\sum_{k=1}^{n} p_{k}(1+i)^{n-k}
$$

o que implica que

$$
F=\sum_{k=1}^{n} p_{k}(1+i)^{-k}
$$

Consideremos agora, sucessivamente, três dos esquemas de financiamento que são mais frequentemente empregados na nossa realidade.

\subsection{Sistema Americano}

No que se denomina de Sistema Americano (SA), nos $n-1$ primeiros períodos somente são pagos os juros devidos ao principal $F$; só havendo amortização quando do pagamento da última prestação.

Isto implica em que se tenha:

$$
a_{k}=0, k=1,2, \cdots, n-1 \quad \text { e } \quad a_{n}=F
$$

Logo

$$
S_{k}=F-\sum_{\ell=1}^{k} a_{\ell}=F \quad \text { para } \quad k=1,2, \cdots, n-1
$$

e

$$
S_{n}=F-a_{n}=0
$$

Portanto:

$$
p_{k}=a_{k}+i S_{k-1}=i F, \quad \text { para } \quad k=1,2, \cdots, n-1
$$

e

$$
p_{n}=a_{n}+i S_{n-1}=F+i F=(1+i) F
$$


Ou seja, periodicamente, pagam-se somente os juros devidos ao principal; só havendo amortização no último período.

Ressalte-se que, neste caso particular, de uma maneira evidente, só há pagamento de juros sobre o principal $F$ financiado; não ocorrendo, pois, anatocismo. Todavia, como visto no caso geral, o princípio financeiro subjacente é o relativo ao regime de juros compostos.

\subsection{Sistema de Amortizações Constantes (SAC)}

Fazendo-se $a_{k}=a$ para $k=1,2, \ldots, n$, como $\sum_{k=1}^{n} a_{k}=n a=F$, tem-se, trivialmente, que:

$$
a_{k}=F / n, \quad \text { e } \quad S_{k}=F-k \frac{F}{n}=F(1-k / n) \quad \text { para } \quad k=1,2, \cdots, n
$$

Por outro lado, escrevendo a relação (2) para as épocas $k-1$ e $k$, e tendo em vista a relação (5), tem-se que:

$$
\begin{gathered}
k-1 \quad: \quad p_{k-1}=a_{k-1}+i S_{k-2}=\frac{F}{n}+i\left(F-\sum_{\ell=1}^{k-2} \frac{F}{n}\right)=\frac{F}{n}+i\left\{F-(k-2) \frac{F}{n}\right\} \\
k: \quad p_{k}=a_{k}+i S_{k-1}=\frac{F}{n}+i\left(F-\sum_{\ell=1}^{k-1} \frac{F}{n}\right)=\frac{F}{n}+i\left\{F-(k-1) \frac{F}{n}\right\}
\end{gathered}
$$

Logo, subtraindo-se membro a membro, segue-se que:

$$
p_{k}-p_{k-1}=-i F / n
$$

Ou seja, as prestações decrescem segundo uma progressão aritmética, cuja razão é $R=-i F / n$.

Sendo que, para $k=1$, se tem:

$$
p_{1}=a_{1}+i S_{0}=\frac{F}{n}+i F=F(i+1 / n)
$$

Novamente, fica evidente que só são pagos juros sobre o principal $F$ financiado, ou sobre uma fração (linearmente decrescente) deste.

\subsection{Sistema de Prestações Constantes}

Sendo o sistema de amortização de dívidas mais popular, consideremos o caso onde seja estabelecido que $p_{1}=p_{2}=\ldots p_{n}=p$; ou seja, que as $n$ prestações sejam todas iguais. Neste caso, da relação de equivalência financeira, tal como dada por (9), segue-se que:

$$
F=p \sum_{k=1}^{n}(1+i)^{-k}
$$

Assim, fazendo-se uso da expressão da soma dos termos de uma progressão geométrica, no caso particular onde a razão e o termo inicial são iguais a $(1+i)^{-1}$, tem-se que:

ou

$$
F=p\left[\frac{1-(1+i)^{-n}}{i}\right]
$$

$$
p=F i /\left[1-(1+i)^{-n}\right]
$$


Quanto às parcelas de amortização, escrevendo-se a relação (2) para as épocas $k+1$ e $k$, tem-se:

$$
\begin{array}{r}
k+1 \quad: \quad a_{k+1}=p-i S_{k}=p-i\left(F-\sum_{\ell=1}^{k} a_{\ell}\right) \\
k \quad: \quad a_{k}=p-i S_{k-1}=p-i\left(F-\sum_{\ell=1}^{k-1} a_{\ell}\right)
\end{array}
$$

Portanto, subtraindo-se membro a membro, segue-se que:

$$
a_{k+1}-a_{k}=i\left(\sum_{\ell=1}^{k} a_{\ell}-\sum_{\ell=1}^{k-1} a_{\ell}\right)=i a_{k}
$$

ou

$$
a_{k+1}=(1+i) a_{k}
$$

Ou seja, as parcelas de amortização crescem segundo uma progressão geométrica de razão igual à soma $1+i$. Sendo que, trivialmente:

$$
a_{1}=p-i S_{0}=p-i F=i F /\left[(1+i)^{n}-1\right]
$$

Sendo que, visto ocorrer o pagamento periódico dos juros sobre o saldo devedor, uma vez mais fica patente não haver cobrança de juros sobre juros.

\subsubsection{Uma Variante: 0 caso da Tabela Price}

Aqui entre nós, sendo corriqueiro em financiamentos habitacionais, costuma-se denominar ser segundo a Tabela Price o caso onde as prestações constantes são mensais, a taxa de juros constante é apresentada sob a forma, dita nominal, expressa em termos de taxa anual com capitalização mensal, com o prazo sendo de $n$ anos.

Neste caso, sendo a correspondente taxa mensal efetiva $i=j / 12$, onde $j$ denota, sob forma unitária, a taxa nominal anual, com capitalização mensal, que tenha sido estipulada, tudo se passa como no caso do Sistema de Prestações Constantes, com $m=12 n$ prestações mensais. Logo, tendo em vista a relação (14), temos:

$$
p=F(j / 12) /\left[1-(1+j / 12)^{-m}\right]
$$

Valendo, com as adequações acima, as demais relações relativas ao caso do sistema de prestações constantes.

\subsection{Comparação em Termos dos Respectivos Totais de Juros Contábeis}

Não obstante, considerada uma mesma taxa periódica de juros $i$ e um mesmo prazo, expresso em um certo número $n$ de períodos, os três casos particulares aqui considerados sejam financeiramente equivalentes, ${ }^{5}$ pois que são financeiramente equivalentes ao mesmo valor financiado $F$, conduzem a distintos totais de juros contábeis.

\footnotetext{
${ }^{5}$ Entretanto, do ponto de vista do tomador do financiamento, a escolha do plano que lhe seja preferivel depende da taxa de juros que reflita seu "custo de oportunidade". Para uma comparação nos casos do SAC e TP, veja-se de Faro (1974).
} 
Isto é, definindo-se o total de juros contábeis, denotado por $J$, como sendo a diferença entre a soma das prestações e o valor $F$ do principal financiado, ou seja

$$
J=\sum_{k=1}^{n} p_{k}-F
$$

cada um dos três casos particulares que foram considerados apresenta um distinto valor para $J$ se $n>1$.

Como, em cada caso, estamos supondo o mesmo principal $F$, a comparação pode ser efetuada com base somente na primeira parcela da relação (15). Ou seja, para saber qual dos três sistemas implica no maior pagamento de juros contábeis, basta confrontar as respectivas somas das $n$ prestações.

Comecemos com os casos mais simples; que são, respectivamente, o do Sistema Americano (SA) e o do Sistema de Amortizações Constantes (SAC).

No caso do SA, temos que o total de prestações, denotado por $P_{1}$, é:

$$
P_{1}=\sum_{k=1}^{n} p_{k}=n i F+F=F(1+n i)
$$

Já no caso do SAC, como as prestações formam uma progressão aritmética, temos que a soma das $n$ prestações $P_{2}$, é:

$$
P_{2}=\sum_{k=1}^{n} p_{k}=\left(p_{1}+p_{2}\right) n / 2
$$

Ora, como já vimos, relação (13), $p_{1}=F(i+1 / n)$. Por outro lado, como a última prestação, $p_{n}$, é dada pela soma da amortização constante, $F / n$, com os juros devidos ao saldo devedor na época $n-1$, saldo devedor este que, de acordo com a relação (5), é também igual a $F / n$, tem-se que $p_{n}=F(1+i) / n$. Portanto:

$$
P_{2}=F\{1+(n+1) i / 2\}
$$

Logo:

$$
P_{1}-P_{2}=(n-1) i F / 2>0 \quad \text { se } \quad n>1
$$

Por conseguinte, em igualdade de condições, paga-se um maior total de juros contábeis no caso de adoção do SA, do que no caso do SAC. ${ }^{6}$

Já no caso do Sistema de Prestações Constantes ou, o que é o mesmo, com as devidas qualificações, da Tabela Price (TP), tem-se que a soma $P_{3}$ das $n$ prestações é:

$$
P_{3}=\sum_{k=1}^{n} p_{k}=n p=n F i /\left[1-(1+i)^{-n}\right]
$$

Entretanto, a comparação direta tanto com $P_{1}$ como com $P_{2}$, não é tarefa trivial. Há que se fazer uso do desenvolvimento em série da potência $(1+i)^{-n}$.

Um caminho alternativo, mais intuitivo, para mostrar que o total de juros contábeis, no caso de adoção da TP, é maior do que quando se adota o SAC, é levar em conta os comportamentos das evoluções dos respectivos saldos devedores (estados da dívida).

\footnotetext{
${ }^{6}$ Esta conclusão é trivial. Basta atentar que, enquanto no SA paga-se sempre juros periódicos sobre o total $F$, no SAC os juros devidos, à exceção dos relativos ao primeiro período, são referentes a frações (linearmente) decrescentes de $F$.
} 
Enquanto que no caso do SAC o saldo devedor decresce livremente, de acordo com a relação $S_{k}=$ $F(1-k / n)$, para $k=1,2, \ldots, n$, pode-se mostrar que no caso de TP (cf. de Faro, 1992, pp. 82-83), o saldo devedor decresce segundo uma função côncava.

Deste modo, tratando-se as respectivas evoluções do saldo devedor como uma função contínua, temos os comportamentos esquematicamente representados na Figura 1.

Figura 1: Comportamentos do Saldo Devedor

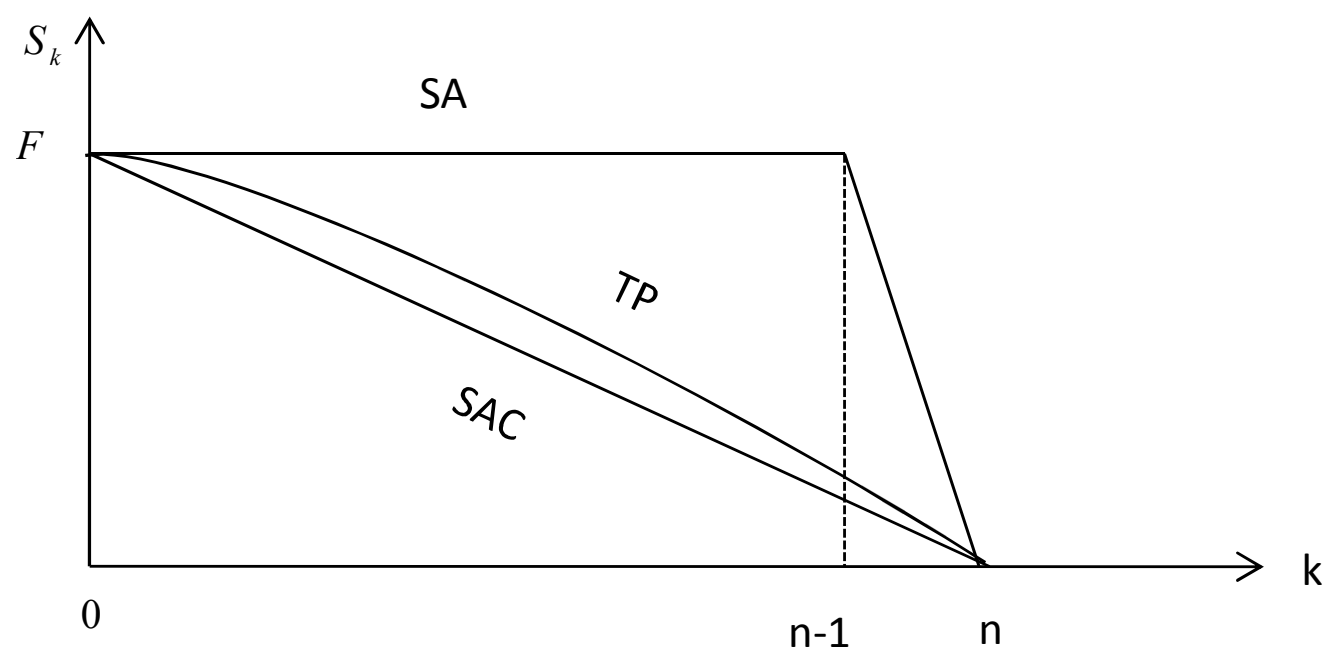

Como, em cada caso, $p_{k}=a_{k}+i S_{k-1}$, tem-se que o total $P$ das prestações é:

$$
P=\sum_{k=1}^{n} p_{k}=\sum_{k=1}^{n}\left(a_{k}+i S_{k-1}\right)=F+i \sum_{k=1}^{n} S_{k-1}
$$

Consequentemente, fica evidente que, dos três sistemas considerados, o que implica no pagamento de maior total de juros contábeis é o SA; seguido pela TP e, após, pelo SAC.

\subsection{De como o BNH Impôs Anatocismo ao SFH: $O$ caso do SIMC}

Como primeiro órgão gestor do Sistema Financeiro de Habitação (SFH), o antigo Banco Nacional de Habitação (BNH), criado em 1964 e extinto em 1986, com suas atribuições sendo acometidas à Caixa Econômica Federal, foi pródigo não só em instituir distintas sistemáticas de correção monetária (indexação), mas também diferentes planos de financiamento habitacional.

Assim, não só tendo introduzido no SFH o SAC, em 1971, o BNH veio a instituir, em 1984 e também no âmbito do SFH, o que denominou de Sistema Misto de Amortização com Prestações Reais Crescentes (SIMC).

A característica básica deste, deveras peculiar, sistema de amortização, é que as primeiras 24 prestações mensais deviam ser fixadas, a preços da data de assinatura do contrato de financiamento, em $85 \%$ do respectivo valor que, considerados o mesmo prazo $n$, em número de meses, e a mesma taxa mensal efetiva $i$, seria determinado segundo o Sistema de Prestações Constantes (ou TP).

A partir da $25^{\mathrm{a}}$ prestação, inclusive, as prestações mensais passavam a crescer segundo uma progressão aritmética cuja razão era dada por uma fórmula pré estabelecida (fórmula esta algo esotérica, mas 
que era justificada, considerada a taxa de juros $i$, a partir da equivalência financeira entre a sequência das $n$ prestações e o principal financiado $F)^{7}{ }^{7}$

Ora, tal procedimento veio a implicar, ao menos para algumas combinações de prazo e de taxa de juros, que o saldo devedor, a preços constantes, não fosse sempre não crescente. Ou seja, poderia ensejar situações onde a condição básica para ausência de anatocismo, tal como expressa pela relação (1), fosse violada. Em outras palavras, o BNH, ao instituir o SIMC, veio a oficializar a possibilidade de ocorrência de anatocismo no âmbito do SFH.

A título de ilustração da possibilidade aventada, seja o caso onde $F=\mathrm{R} \$ 100.000,00, n=240$, meses e $i=1 \%$ a.m. Tendo em vista a relação (14) e a característica do SIMC, tem-se que a primeira prestação seria igual a:

$$
p_{1}=0,85 \times 100.000 \times 0,01 /\left[1-(1+0,01)^{-240}\right]=R \$ 935,92
$$

Por outro lado, como $i F=0,01 \times 100.000=\mathrm{R} \$ 1.000,00$, teríamos uma situação onde a prestação inicial não cobriria os juros devidos ao principal. Ou seja, formalmente, teríamos uma amortização negativa, com consequente crescimento do saldo devedor (face à incorporação dos juros não cobertos pela prestação). Por conseguinte, passaríamos a ter juros devidos a juros; isto é, teríamos a ocorrência de anatocismo. ${ }^{8}$

\section{O CASO DE PRESTAÇÕES EM ATRASO}

Vejamos agora a situação, que costuma ser frequente e é fonte de interpretações equivocadas, em especial no âmbito do judiciário, em que há a ocorrência de prestação em atraso.

Em tal situação, para que continue havendo a equivalência financeira entre o valor financiado e a nova, face ao atraso, sequência de prestações, é inescapável, como iremos mostrar, que além de multas, o que pode ser considerado abusivo, haja a cobrança de juros, à taxa $i$ estipulada no contrato de financiamento, sobre qualquer prestação em atraso. Ou seja, em tal eventualidade, para que o devedor não se locuplete em detrimento do credor, há que haver a ocorrência de anatocismo.

Retornando ao caso geral e buscando facilitar a exposição, suponha que não seja paga, na data devida, a primeira prestação (que denotamos por $p_{1}$ ).

Admita-se, agora, que a prestação em atraso venha a ser paga, juntamente com a prestação original $p_{2}$, na data de vencimento desta última (fim do segundo período). Representando-se por $p_{2}^{\prime}$ o valor que deve ser pago no fim do segundo período, e supondo que as demais prestações sejam todas pagas nas respectivas datas devidas, e com seus respectivos valores originais, segue-se que o financiamento $F$ passa a dever ser resgatado mediante o pagamento da sequência de prestações $p_{1}^{\prime}, p_{2}^{\prime}, p_{3}^{\prime}, \ldots, p_{n}^{\prime}$ com $p_{1}^{\prime}=0$ e $p_{k}^{\prime}=p_{k}$ para $k=3,4, \ldots, n$. Resta, pois, determinar o valor de $p_{2}^{\prime}$.

Em tal situação, para que seja mantida a equivalência financeira entre o valor financiado $F$ e a nova sequência de prestações, devemos ter (face à relação (8)).

$$
\begin{aligned}
F & =\sum_{k=1}^{n} p_{k}^{\prime} \prod_{\ell=1}^{k}\left(1+i_{\ell}\right)^{-1} \\
& =0+p_{2}^{\prime}\left(1+i_{1}\right)^{-1}\left(1+i_{2}\right)^{-1}+\sum_{k=3}^{n} p_{k} \prod_{\ell=1}^{k}\left(1+i_{\ell}\right)^{-1}
\end{aligned}
$$

\footnotetext{
${ }^{7}$ Para uma análise abrangente veja-se de Faro (op. cit., 1992, pp. 73-81).

${ }^{8} \mathrm{~A}$ bem da verdade, nem sempre teríamos a ocorrência de anatocismo. No caso da ilustração acima, não teríamos anatocismo se, por exemplo, o prazo $n$ fosse inferior a 190 meses.
} 
Ora, tendo em vista a sequência de prestações originais, temos que, subtraindo, membro a membro, a relação (8’) da relação (8):

$$
0=p_{1}\left(1+i_{1}\right)^{-1}+p_{2}\left(1+i_{1}\right)^{-1}\left(1+i_{2}\right)^{-1}-p_{2}^{\prime}\left(1+i_{1}\right)^{-1}\left(1+i_{2}\right)^{-1}
$$

do que decorre que

$$
p_{2}^{\prime}=p_{1}\left(1+i_{2}\right)+p_{2}
$$

ou face à relação (2)

$$
p_{2}^{\prime}=\left(a_{1}+i_{1} F\right)\left(1+i_{2}\right)+p_{2}=a_{1}\left(1+i_{2}\right)+i_{1}\left(1+i_{2}\right) F+p_{2}
$$

Fica, pois, patente que, para que seja mantida a equivalência financeira entre o valor financiado e a (nova) sequência de prestações, a prestação em atraso deve ser acrescida de juros à taxa $i_{2}$. Em outras palavras, como o saldo devedor é acrescido de juros sobre juros, há que ocorrer anatocismo.

\section{CONCLUSÃO}

Fixando atenção nos casos da Tabela Price e do Sistema de Amortização Constantes, que são os dois esquemas de amortização de dívidas prevalentes no chamado Sistema Financeiro de Habitação, e também no Sistema Americano, todos eles meros casos particulares do sistema mais geral que estudamos, fez-se aqui isofismável que se conformam com os fundamentos do regime de juros compostos.

Todavia, o que poderia se afigurar como paradoxal, desde que, em cada um dos três casos, não haja prestação em atraso, não há a presença de anatocismo.

Ou seja, em conclusão, conquando anatocismo implica em juros compostos, o regime de juros compostos não, necessariamente, acarreta anatocismo.

\section{BIBLIOGRAFIA}

de Faro, C. (1974). DIVID: Um programa flexível para construção do estado de uma dívida. Ensaios Econômicos da EPGE 20, IBRE/FGV.

de Faro, C. (1992). Vinte Anos de BNH. Editoras da Universidade Federal Fluminense e da Fundação Getulio Vargas.

de Faro, C. (2009). Anatocismo: O Direito (a Justiça) e a Matemática Financeira. Revista de Direito do Tribunal de Justiça do Estado do Rio de Janeiro, 80:120-129. Colaboração de Sergio Guerra.

de Faro, C. \& Lachtermacher, G. (2012). Introdução à Matemática Financeira. Editoras FGV e Saraiva, Rio de Janeiro.

de Holanda Ferreira, A. B. (1999). Novo Aurélio, O Dicionário da Língua Portuguesa, Século XXI. Editora Nova Fronteira. 


\section{A. APÊNDICE - O CASO DE CONCESSÃO DE CARÊNCIA}

Entendendo-se como havendo carência de $c$ períodos, o caso onde a primeira prestação periódica somente seja devida após decorridos $c+1$ períodos, $\operatorname{com} c \geq 1$, da data da liberação do financiamento $F$, o propósito aqui será o de evidenciar que, não necessariamente, ter-se-á a ocorrência de anatocismo, durante a carência.

Para fixarmos ideias, consideremos o caso de um financiamento no valor de 100.000 u.c., à taxa mensal, constante, de $10 \%$, pelo prazo total de 6 meses, com 2 meses de carência.

Considerem-se as duas seguintes situações:

1 - na primeira, admita-se que tenha sido acordado pelas partes interessadas, que, durante os dois meses do prazo de carência, a taxa de $10 \%$ a.m. seja de juros simples. Com os pagamentos mensais, após a carência, seguindo o SA a partir do saldo devedor $S_{2}$, tal como apurado no fim dos dois meses.

Como

$$
S_{2}=100.000(1+2 \times 0,1)=120.000
$$

teremos a seguinte sequência de prestações: $p_{1}=p_{2}=0, p_{3}=p_{4}=p_{5}=12.000$ e $p_{6}=132.000$. Nesta eventualidade, como, durante a carência, a taxa de juros acordada foi de juros simples, não houve capitalização de juros. Ou seja, não houve anatocismo, durante a carência.

Entretanto, como as prestações são calculadas a partir do valor do empréstimo, acrescido dos juros relativos ao prazo de carência, temos a presença de anatocismo na fase de amortização do débito.

A questão que se coloca é saber qual a taxa mensal que está implícita nesta situação.

Fazendo-se uso de uma calculadora financeira, pode-se constatar que a taxa efetiva, de juros compostos, que está subjacente é $i^{*} \cong 9,83 \%$ a.m.

2 - na segunda situação, será suposto que, durante o prazo de carência, a taxa de $10 \%$ a.m. seja de juros compostos.

Neste caso, há a capitalização de juros, com o saldo devedor $S_{2}$ passando a ser:

$$
S_{2}=100.000(1+0,1)^{2}=121.000
$$

Admitindo que, agora, tal como na primeira situação se tenha a adoção do SA, segue-se que a sequência de prestações será: $p_{1}=p_{2}=0, p_{3}=p_{4}=p_{5}=12.100$ e $p_{6}=133.100$.

Sendo que, nesta eventualidade, é fácil constatar que a taxa de juros compostos que está implícita é, exatamente, a taxa pactuada de $10 \%$ a.m. 